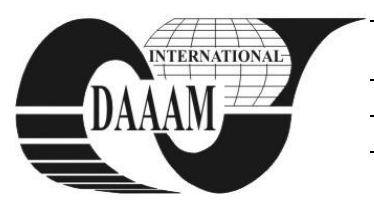

Annals of DAAAM for 2011 \& Proceedings of the 22nd International DAAAM Symposium, Volume 22, No. 1, ISSN 1726-9679 ISBN 978-3-901509-83-4, Editor B. Katalinic, Published by DAAAM International, Vienna, Austria, EU, 2011 Make Harmony between Technology and Nature, and Your Mind will Fly Free as a Bird Annals \& Proceedings of DAAAM International 2011

\title{
EXPERIMENTAL ANTENNA DESIGN BASED ON NATURAL CONSTRUCTIONS
}

\author{
MATYAS, J[iri] \& VLCEK, K[arel]
}

\begin{abstract}
With the help of mathematical calculations it is possible to clearly define, how a passive antenna, part of modern communicational devices, could look like. Various computer programs are used for the development of antennas. These programs allow us to create quite precise outputs of passive antenna designs. This article describes the possibility of inspiration by nature in the development of passive antenna parts. The study of shapes of certain kinds of plants and possibly even structures created by animals may significantly contribute to new findings in the design of communication antenna systems
\end{abstract}

Key words: antenna, construction, $P C B$, design

\section{INTRODUCTION}

There are various designs of PCB type antennas. The purpose of various structures is in the predetermined requirements of broadcast bandwidth in which the PCB antenna will be operated. The design of PCB antennas is most usually carried out with the help of computer programs, so called antenna studies, which can even depict the simulation for spreading of signal of the defined antenna model. This way of development of antennas is very comfortable and fast, especially in case of PCB type antennas (Zhurbenko, 2010). In nature there are countless structures and constructions which may very significantly contribute to the design of antenna modules. A better choice of material and innovative designs are an assurance of high quality antenna system (Antony, 2003).

The designing of antennas is dependant on the type of device, for which they will be used later on. It is also very significant, for what bandwidth the antenna is constructed. This article describes the selection of natural constructions in a more general way. Because not every structure may be fully compliant with the required device and frequency range, for which the antenna is supposed to be used, and it is only up to the constructor which structure he chooses. Plants have very well adapted branches and the entire habitat for the distribution of nutrients from roots up to the fruits. The roots are used by the plants for the reception of water and nutrients, leafs for the reception of sun and in a smaller part also nutrients (Miron, 2006). It is possible to use the flowers which often have very ragged structure for the constructions. In case of the conifers it is possible to observe the arrangement of pins which reminds the Yagi type of antenna in the way it looks (Balanis, 1997). Even the simulations of computer models may help to find a suitable construction.

The process used to simulate antenna construction created on the basis of mathematical calculations without certain physical testing can not be immediately applied into practical usage. Most materials for the production of antennas can actually behave in a different way than in simulated environment. It is possible to simulate even various effects of interference and materials. But it is very difficult to simulate everything in a way that corresponds with the subsequent actual usage. If antenna construction constructed on the basis of natural structure is tested, it is best to test it in actual conditions and not only by simulation. Actual tests will show whether the tested construction is perspective for further experiments and development or not. Simulation and measurement of virtual antenna models can gain certain results but cannot be conclusively relied upon.

\section{WAYS OF CREATION OF EXPERIMENTAL ANTENNA CONSTRUCTIONS}

Finding a proper way of creation of antennas on the basis of inspiration from nature can be done in multiple ways. In case of smaller constructions the structure can be drawn and then tested on a prototype of PCB antenna. This way is the least timeconsuming one and is very popular. Another step for the creation of antenna prototype is the possibility of usage of copper wires, tubes and metal sheets (Prochazka, 1999; Constantine, 2008). These types of antennas made of other materials than with the help of PCB technology are more complex, but it is possible to create interesting types of antenna constructions with plausible look based on natural pattern. This way can for example be used to create antennas that cannot be created with the help of PCB technology.

In case of these experimental antenna prototypes created in a laboratory a high performance is not expected. In case of these specimens the main concern is the examination of suitability and usability of constructions. If the construction proves to be useful, it can be scaled up or down and modified for the concrete requested bandwidth. It may not be possible to modify some constructions for concrete bandwidths (e.g. for LTE 2.6 GHz bandwidth) (Holma \& Toskala, 2009), but it is possible to use them in another wave spectres. The determination of suitability of the specimen of the newly designed antenna for the implementation in the practical usage is a key factor of constructions. A good decision is made after thorough consideration on the basis of required and achieved results obtained from measurements of the individual specimens.

\section{SELECTION OF NATURAL STRUCTURES}

An important factor for success and subsequent execution of specimens of antennas is a very careful selection of basic natural structure which will serve as a basis for final antenna. Even a structure that looks good in the beginning may show bad properties in the stage of testing. The nature is inspiring, but the physical element for the broadcast of signal must be respected. There is shown in the Tab. 1 the individual specimens of natural constructions, which can be used as a basis for construction of experimental antenna prototypes. It lists several specimens such as leaf, flower, branch of spruce, habit of tree and bee cell. The difficulty of their feasibility is described for each specimen. This difficulty of feasibility of constructions depends upon the look of the natural construction.

It is possible to use PCB technology for the horizontal planes. If the original from nature is too complicated, it is 
possible to create an antenna through other procedures than PCB technology, for example through copper metal sheets and sticks.

\begin{tabular}{|c|c|c|c|c|}
\hline 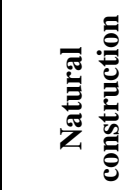 & 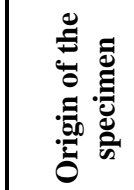 & 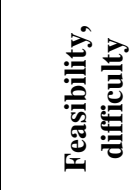 & 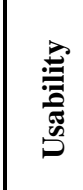 & 矛 \\
\hline Leaf & $\begin{array}{l}\text { plant } \\
\text { origin }\end{array}$ & easy & yes & satisfying \\
\hline Flower & $\begin{array}{l}\text { plant } \\
\text { origin }\end{array}$ & easy & yes & satisfying \\
\hline $\begin{array}{c}\text { Branch of } \\
\text { spruce } \\
\end{array}$ & \begin{tabular}{|l|} 
plant \\
origin
\end{tabular} & moderate & yes & satisfying \\
\hline \begin{tabular}{|c|}
$\begin{array}{c}\text { Habitus } \\
\text { of tree }\end{array}$ \\
\end{tabular} & \begin{tabular}{|l|} 
plant \\
origin
\end{tabular} & increased & yes & \begin{tabular}{|l} 
less \\
satisfying
\end{tabular} \\
\hline Bee cell & $\begin{array}{l}\text { animal } \\
\text { origin }\end{array}$ & easy & yes & satisfying \\
\hline
\end{tabular}

Tab. 1. Sample of evaluation of feasibility of sources of natural constructions

\section{RESULTS}

The newly created experimental constructions which were subjected to testing in laboratory can be moved on to long-term testing and subsequent production. In the final phase the antennas are planted into concrete devices. The main reason for these constructions to appear as perspective in case of usage in some devices is that their shape allows more sophisticated broadcast of signal than in case of antennas designed strictly with the help of mathematical apparatus.

The purpose of this article is not to point to the abilities of plants, the way they are able to use the energy of sun to create nutrition, but it is suitable to point to the ingenuity of natural constructions. A plant is naturally adapted by its construction to better admission of energy of sun, water and so on. Thus the application of such findings is appropriate even in case of usability in signal broadcast. The disadvantage of such antenna structures created on the basis of copying of the nature may only be their problematic modification for the best possible radiation characteristics.

The miniaturization of mobile communication devices is advancing and it is thus necessary to also miniaturize the antenna part. Mobile phones and other communicational devices using wireless networks work most usually in such frequency bandwidths which are not demanding a high performance of the antennas from the constructional point of view. It is always necessary to take into consideration the requirements of the given device. Nevertheless most of the frequency bandwidths $(850 / 900 / 1800 / 1900 \mathrm{MHz}$ a in case of higher $2.4 \mathrm{GHz}, 2.6 \mathrm{GHz}$ ) have quite small antenna modules, which are much better to produce than large antenna systems. Regardless to increasing requirements of the speeds in the wireless communicational networks, some of the natural structures may even be incorporated to MIMO system (Balanis, 2008), which could result in the achievement of interesting transfer capacities. The boundaries for the broadcasting of signal are known in advance. Regardless to that it can be used the new findings in the natural constructions to improve the adjustment of models of antenna constructions for better properties of signal radiation either for antennas produced as PCB or for different types and if it is necessary for fine tune the design of the antenna into the required state. In case of experimental specimens it appears that the usability of natureinspired constructions for the broadcast of signal in bandwidths $1900 \mathrm{MHz}, 2.4 \mathrm{GHz}$ and $2.6 \mathrm{GHz}$ is perspective. The experimental antenna designs based on natural construction are shown in Fig. 1 and Fig. 2.

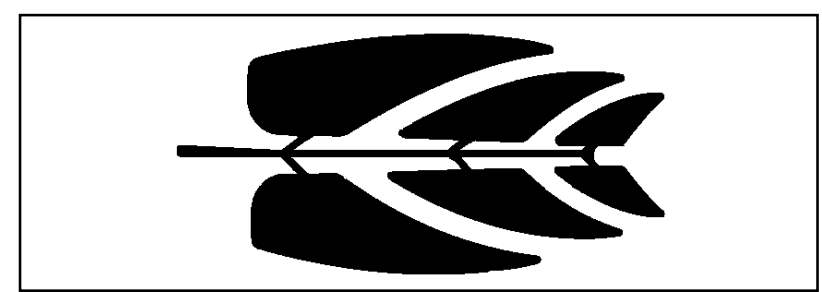

Fig. 1. The PCB antenna design based on the structure of the leaf

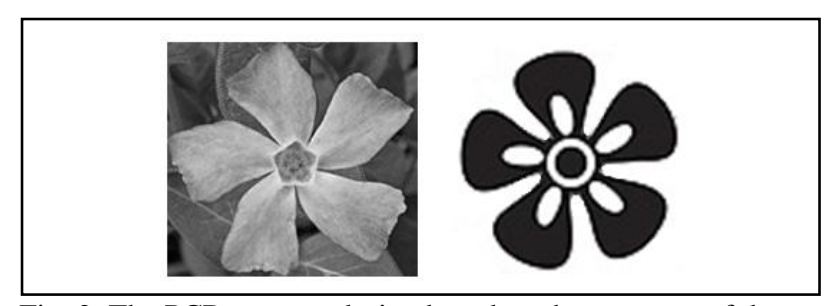

Fig. 2. The PCB antenna design based on the structure of the blossom

\section{CONCLUSION}

In the next step of the research the experimental specimens of the antenna constructions will be subjected to reduction. It will be possible to mount the reduced antenna element into a device the size of modern mobile phones. The transmission rates for modern mobile networks are constantly increasing, for example the frequencies for LTE networks are up to $2.6 \mathrm{GHz}$. It is thus necessary to bear on mind that the frequencies of higher order do not need an antenna large in size, but with the growing requirements of speed and stability of data it will be necessary to multiply the signal gain through MIMO system consisting of several similar antenna modules and constructed most often as PCB type antenna. In case of such antennas it will be possible to partially implement the knowledge based on natural constructions for the improvement of transfer properties for example into MIMO system.

\section{ACKNOWLEDGEMENTS}

The work behind the article was supported by the Internal Grant Agency of Tomas Bata University in Zlin with No. IGA/42/FAI/11/D.

\section{REFERENCES}

Antony, J. (2003). Design of Experiments for Engineers and Scientists, Butterworth-Heinemann, ISBN 0750647094, Oxford

Balanis, C. A. (1997). Antenna Theory : Analysis and Design, John Wiley \& Sons, Inc., ISBN 0-471-59268-4, New York

Balanis, C. A. (2008). Multi-Antenna Systems for MIMO Communications, Morgan \& Claypool, ISBN 9781598290899, San Rafael

Holma, H. \& Toskala, A. (2009). LTE for UMTS : OFDMA and SC-FDMA based radio access, John Wiley \& Sons, Inc., ISBN 0470994010, New York

Miron, D. B. (2006). Small Antenna Design, Elsevier Inc., ISBN 978-0-7506-7861-2, Oxford

Prochazka, M. (1999). Mikrovlnne dily a anteny pro prenos VF energie na DM, CM a MM vlnach. Konstrukcni elektronika a radio, pp. 3-40, ISSN 1211-3557, Vol. 4, No. 5, 1999

Zhurbenko, V. (2010). Passive microwave components and antennas, InTech, ISBN 978-953-307-083-4, Rijeka 